\title{
Glycemic index (GI) and glycemic load (GL) values for dried bisr and tamr dates
}

\author{
Amjad H. Jarrar', Afaf Kamal-Eldin², Mo'ath Bataineh', Ayesha S. Al Dhaheri* \\ ${ }^{1}$ Department of Nutrition and Health, College of Food and Agriculture, United Arab Emirates University, Al Ain - 15551, United Arab Emirates; \\ ${ }^{2}$ Department of Food Science, College of Food and Agriculture, United Arab Emirates University, Al Ain - 15551, United Arab Emirates
}

\section{A B S TR A C T}

\begin{abstract}
Background: Date fruits can be consumed at different stages of maturity and thus might vary in glycemic response. Therefore, this study aims to evaluate the nutritional composition, glycemic index (GI) and glycemic load (GL) values of dried Bisr (mature unripe) and Tamr (mature ripe) dates. Methods: Fifteen healthy female participants (18 and 25 years), were recruited to assess the GI and GL values of dried Bisr and dried Tamr dates. Each participant was tested in three different times. Trials were separated by 1 week and proceeded in a randomized counterbalanced manner. Anthropometrics and food records were obtained for all participants. Results: Proximate analysis revealed significant differences between Bisr and Tamr dates in moisture, ash, fat, protein, and fiber content $(P<0.05)$, whereas, carbohydrate and energy contents were comparable $(P>0.05)$. The incremental area under the blood glucose response curve was higher $(164.5 \pm 47.8)$ for the standard food in comparison with dried Bisr $(88.5 \pm 24.1, P<0.0001)$ or dried Tamr dates $(88.2 \pm 27.9$, $P<0.0001)$, whereas, no significant differences were detected between the test foods $(P>0.05)$. Both GI (Bisr: $54.6 \pm 15.2$ vs. Tamr: 54.3 \pm 14.3 ) and GL (Bisr: 13.65 vs. Tamr: 13.58) were not significantly different between the test food items $(P>0.05)$. Conclusion: Dried date fruits induce similar glycemic responses regardless of their maturity stage.
\end{abstract}

Keywords: Glycemic index; Glycemic load; Bisr; Date fruits; Tamr

\section{INTRODUCTION}

The fruit of the date palm (Phoenix dactylifera, L.) is consumed worldwide and is a dietary staple for many people in the Arabic world. Dates occupy about 30\% of the cultivated land in the United Arab Emirates (UAE) producing about 760,000 metric tonnes (MT) of fruit, which is about $11.3 \%$ of the world's production (Aldhaheri et al., 2004: Kamal-Eldin et al., 2012: MAF, 2000). With this vast increase in date fruit production in the UAE, processing and industrialization of date fruits to produce new value-added products is highly warranted.

Date fruits are consumed at three different stages of maturation: mature but unripe, namely Bisr or Khalal $50 \%$ moisture), ripened, namely Rutab (30\%-35\% moisture), and mature, namely Tamr (10\%-30\% moisture) (KamalEldin et al., 2012). Date fruits are rich in nutrients such as carbohydrates (total sugars, $44 \%-88 \%$ ), proteins (2.3-5.6\%), fibers $(6.4 \%-11.5 \%)$, fatty acids $(0.2 \%-0.5 \%)$, salts, minerals, and vitamins (Alkaabi et al., 2011). Currently, a very small percentage of date fruits is consumed at the firm and crunchy Bisr stage, a small percentage at the Rutab or ripe stage, and the largest percentage is consumed as fresh or dried pitted dates at the Tamrstage (Degefa et al., 2017). Bisr dates contain more of the health-promoting dietary fiber and less sugar than Rutab and Tamr (Elleuch et al., 2011: Elleuch et al., 2008). Nevertheless, the physiological transformation from Bisr to Rutab is interrupted in a large percentage of date fruits, which are then wasted on the trees and consequently discarded or at best used as animal feed. Consequently, if they were to be valorized at the Bisr stage, losses of date fruits might be minimized. Moreover, some varieties that are not preferred by consumers at the Tamr stage might perform better at the Bisr stage. In addition, drying of Bisr dates will enable their use as additives in breakfast cereals and baked products, alone or with other fruits and/or nuts.

It is estimated that globally more than 135 million people have Type 2 diabetes mellitus (DM) with United States

\footnotetext{
*Corresponding author:

Ayesha S. Al Dhaheri, Nutrition and Health Department, College of Food and Agriculture, United Arab Emirates University, Al Ain, UAE.

E-mail: ayesha_aldhaheri@uaeu.ac.ae
} 
having more than 20 million diabetic people (15\% of all DM patients) (Li et al., 2011). According the International Diabetes Federation (IDF), in 2015, the UAE was ranked $13^{\text {th }}$ worldwide for prevalence of Type $2 \mathrm{DM}$, which is due to changes in lifestyle and dietary habits (IDF, 2015). High intake of dates (date fruits) in the UAE could be a contributing factor to the high prevalence of diabetes and obesity among UAE individuals. Despite their high sugar contents, Tamr dates were identified to have low glycemic load (GL) value after consumption (Alkaabi et al., 2011: Miller et al., 2003: Miller et al., 2002). Whereas, Bisr dates have lower levels of soluble sugars compared with Tamr dates, which might have an effect on their glycemic index (GI) value (Eltayeb et al., 1999). Health benefits of low GI foods with particular reference to obesity, diabetes, and cardiovascular diseases were previously highlighted (Gilbertson et al., 2001). The current study aims to evaluate the nutritional composition, GI and GL values of dried Bisr and dried Tamr dates.

\section{EXPERIMENTAL METHODS}

\section{Subjects}

All participants were recruited from United Arab Emirates University (UAEU) to voluntarily participate in the study. E-mail invitations, posters displayed in different UAEU buildings and words of mouth were used as means for subject recruitments. Fifteen healthy female participants aged between 18 and 25 years old were recruited from the female campus of the UAEU. Taking into consideration that participants' characteristics such as age, sex, bodymass index and ethnicity are not supposed to influence GI determination(Wolever et al., 2003). In addition, similar studies have been conducted on female subjects only (Amano et al., 2004: Al Dhaheri et al., 2015). Participants did not take part if they had any of the exclusion criteria, defined as: aged less than 18 or more than 25 years old; if they had their menstrual cycle; body mass index (BMI) value more than or equal to $25 \mathrm{~kg} / \mathrm{m}^{2}$ or less than $18.5 \mathrm{~kg} / \mathrm{m}^{2}$; fasting plasma glucose (FPG) value of more than $6.1 \mathrm{mmol} / \mathrm{l}$; and having a known history of impaired glucose tolerance or DM. Participants completed a health-screening questionnaire before taking part in the study to make sure that they meet the inclusion criteria. Those who met the inclusion criteria were given complete details about the study protocol and the chance to ask questions. Informed written consent was obtained from all participants before commencement of the study protocol. In addition, participants were asked to fast for 12 hours the night before the test. The day before the GI test, participants were asked to minimize their participation in any vigorous physical activity, to limit their intake of caffeine-containing drinks, and not to smoke.
The present study was conducted according to the guidelines laid down in the Declaration of Helsinki and all procedures involving human subjects were approved by the United Arab Emirates University Scientific Research Ethics Committee (UAEU, Reference Number - 516/09).

\section{Anthropometric measurements}

Anthropometric measurements were carried once for each participant, prior to recruitment, to confirm that the subject fit the inclusion criteria. All measurements were in a fasting state after a 12-hour fast, with subjects wearing light clothes and no shoes. Each measurement was taken three times and averaged. Measurements included height in $\mathrm{cm}$ using a stadiometer (Seca Stadiometer, Seca Ltd, Birmingham, UK) (Gibson, 2005), body weight in kg, fat mass (FM) and fat free mass (FFM) using the Tanita Segmental Body Composition Analyzer (Tanita BC-418 Ltd, Tanita UK) (Chang et al., 2013). BMI was calculated by dividing the weight in $\mathrm{kg}$ by the height in meters, squared: BMI = weight $(\mathrm{kg}) /$ height $^{2}\left(\mathrm{~m}^{2}\right)$, using the WHO definition for BMI classification (WHO, 2006).

\section{Test foods}

Dried Bisr and Tamr dates were freshly harvested from the UAE date variety Neghal, which was procured at the College of Food and Agriculture farm (Al-Foah Farm, UAEU). This date variety was selected based on its lack of bitterness at the Bisrstage. The Bisr date fruits were sorted, pitted, washed, blanched and dried. Sun-drying experiments were performed in a direct solar dryer for 7 days until the weight stopped decreasing. The initial moisture content of the fresh Bisr fruit was around $62 \%$, and was reduced by drying to $6 \%$, leading to a water activity of 0.53 in the dried samples.

\section{Analytical methods}

Proximate analyses of moisture, protein, fat, fiber and ash content were conducted at the Nutrition and Health Department laboratories of UAEU for each test food using standard analytical methods described by the Association of Official Analytical Chemists (AOAC and Horwitz, 2003). Each test was performed in triplicate and the results averaged to minimize possible systematic and random experimental errors. Carbohydrate content was estimated by subtraction of the mean percentage values of the moisture, ash, protein, fat, and crude fiber from 100 (Bouaziz et al., 2013). Total energy content was calculated by multiplying the amounts of protein, carbohydrate and fat by factors of 4, 4 and 9 respectively (Dashti et al., 2001).

\section{Study protocol}

The method used for the measurement of GI was adapted from that described by Wolever et al. (Wolever et al., 1991), and Brouns et al. (Brouns et al., 2005) and 
in line with procedures recommended by the FAO/ WHO (1998) (FAO/WHO, 1998). The test meals and a reference food (glucose) were administered to subjects following a randomized, repeated-measures design, with each subject serving as his/her own control. Subjects tested the reference food three times and each test food for one time only. Food testing was carried out on separate occasions with at least a 1-day gap between measurements to minimize any carry-over effects. The reference food provided was $25 \mathrm{~g}$ of glucose powder (glucose dextrose monohydrate) dissolved in $200 \mathrm{ml}$ of water. Test foods were tested in equivalent available carbohydrate amounts of $25 \mathrm{~g}$ and was also served with $200 \mathrm{ml}$ water. Subjects were encouraged to consume the reference or test foods within 15 minutes and to minimize physical activity during the testing time. Available carbohydrate content was used to determine the experimental portion (g) that would provide $25 \mathrm{~g}$ of available carbohydrates from each test food.

\section{Blood glucose measurements}

Blood samples were obtained using the OneTouch ${ }^{\circledR}$ UltraSoft ${ }^{\mathrm{TM}}$ Adjustable Blood Sampler (Johnson and Johnson, Middle East, Inc.) which uses the OneTouch ${ }^{\circledR}$ UltraSoft $^{\mathrm{TM}}$ pen and OneTouch ${ }^{\circledR}$ FinePoint $^{\mathrm{TM}}$ lancets. Capillary blood was collected from the third finger on the left hand. Several reports suggested the use of capillary blood rather than venous blood sampling for reliable GI testing (Brouns et al., 2005: FAO/WHO, 1998). A $5 \mu \mathrm{L}$ blood sample was collected in the microcuvette by capillary action. Blood glucose was measured using the HemoCue Glucose $201^{+}$portable system (HemoCue ${ }^{\circledR}$ Ltd, UK). Calibration of the blood glucose meters was done daily according to the manufacturers' instructions.

A fasting blood sample ( 0 minutes) was obtained before subjects had consumed any food and further blood samples were obtained at 15, 30, 45, 60, 90 and 120 minutes after the consumption of each food.

\section{Calculation of glycemic response measurements}

The incremental area under the blood glucose response curve (IAUC), ignoring the area beneath the baseline, was calculated geometrically (FAO/WHO, 1998). The IAUC for dried Bisr and Tamr dates eaten by each subject was expressed as a percentage of the mean IAUC for the reference food consumed by the same subject as follows:

$\mathrm{GI}=$ (IAUC for the test food containing $25 \mathrm{~g}$ of available $\mathrm{CHO} / \mathrm{IAUC}$ of a reference food with an equal available CHO portion) $\times 100($ FAO/WHO, 1998: Kris et al., 2010: Dashti et al., 2001)

The GL of a serving of each test food was calculated according to the following formula:
$\mathrm{GL}=(\mathrm{GI}$ of test food $\times$ amount of available $\mathrm{CHO}$ in a serving of test food (g))/100 (FAO/WHO, 1998: Kris et al., 2010).

\section{STATISTICAL ANALYSES}

Analyses were performed to ensure no violations of the assumptions of normality, linearity, collinearity, and homoscedasticity. Sphericity was tested with Mauchly's test. When the assumption of sphericity was violated, the degrees of freedom were corrected using GreenhouseGeisser. Data were analyzed using IBM SPSS statistics 23 (IBM SPSS, Chicago, USA). All data were presented as means \pm standard deviation. Effects of treatment, time and trial order on study variables were analyzed using repeated measure ANOVA, followed by Bonferroni post hoc adjustment for multiple pairwise comparisons when needed. Effect size was reported as partial eta squared $\left(\eta_{\mathrm{p}}{ }^{2}\right)$. Level of significance was set at $P<0.05$.

G*Power 3.1.9.2 software was used for sample size calculation for ANOVA with repeated measures. The calculation revealed the need for a sample size of 15 participants to detect a medium effect size (0.4) with significance level set at 0.05 and power as 0.90 . Consequently, a total of fifteen participants were used for GI testing of a single food which is more than the minimum requirement recommended by the International Standards Organisation (ISO 26642:2010 standard) for GI testing (ISO, 2010).

\section{RESULTS}

\section{Characteristics of the study population}

Participants' baseline characteristics are presented in Table 1. There were no withdrawals or adherence-based withdrawals from the study, and all participants met the adherence requirements during data collection period.

\section{Chemical composition of test foods}

The proximate analyses data per $100 \mathrm{~g}$ of fresh weight for the test foods are shown in Table 2. Extensive variation is evident between dried Bisr and dried Tamr dates for

Table 1: Participants' baseline characteristics $(n=15)$

\begin{tabular}{lc}
\hline Characteristics & Mean \pm SD \\
\hline Age $($ years $)$ & $21.4 \pm 1.8$ \\
Height $(\mathrm{m})$ & $1.61 \pm 0.05$ \\
Weight $(\mathrm{kg})$ & $56.3 \pm 4.5$ \\
BMI $\left(\mathrm{kg} / \mathrm{m}^{2}\right)$ & $21.6 \pm 1.7$ \\
Fat mass $(\%)$ & $28.4 \pm 4.1$ \\
Fat mass $(\mathrm{kg})$ & $16.2 \pm 3.3$ \\
Free fat mass $(\%)$ & $71.7 \pm 3.9$ \\
Free fat mass $(\mathrm{kg})$ & $40.3 \pm 2.8$ \\
\hline
\end{tabular}

Emir. J. Food Agric • Vol 31 • Issue 2 • 2019 
Table 2: Proximate analysis of dried Bisr and dried Tamr dates ( $\mathrm{g} / 100 \mathrm{~g}$ fresh weight basis)

\begin{tabular}{lccc}
\hline Variables & $\begin{array}{c}\text { Dried Bisr } \\
\text { dates }\end{array}$ & $\begin{array}{c}\text { Dried Tamr } \\
\text { dates }\end{array}$ & $\boldsymbol{P}$ value \\
\hline Moisture $(\mathrm{g})$ & $6.1 \pm 0.21^{+}$ & $15.2 \pm 1.41$ & 0.012 \\
Ash $(\mathrm{g})$ & $3.1 \pm 0.14$ & $2.2 \pm 0.14$ & 0.03 \\
Fat $(\mathrm{g})$ & $0.2 \pm 0.03$ & $0.1 \pm 0.01$ & 0.019 \\
Protein $(\mathrm{g})$ & $2.9 \pm 0.24$ & $2.1 \pm 0.22$ & 0.03 \\
Crude Fiber (g) & $21.3 \pm 2.0$ & $9.6 \pm 1.4$ & 0.015 \\
Carbohydrate $(\mathrm{g})$ & $66.6 \pm 1.4$ & $70.8 \pm 2.2$ & 0.097 \\
Energy (Kcal) & $279.8 \pm 6.83$ & $292.5 \pm 9.77$ & 0.453 \\
\hline
\end{tabular}

${ }^{+}$Mean \pm SD

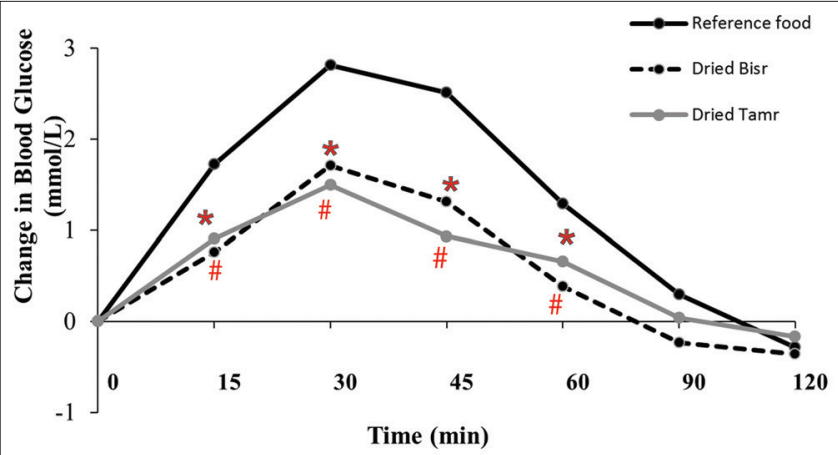

Fig 1. The blood glucose response curves for the reference and the test foods. *Reference food differs significantly from dried Bisr $(P<0.05)$. "Reference food differed significantly from dried Tamr date $(P<0.05)$.

moisture (6.1 \pm 0.71 vs. $15.2 \pm 0.85 ; P=0.012)$, and total crude fiber content $(21.3 \pm 2.0$ vs. $9.6 \pm 1.4 ; P=0.015)$ respectively. Whereas, the carbohydrate and the total energy contents for the tested foods were comparable $(P>0.05)$.

\section{Glycemic response and IAUC values}

Figure 1 describes the glycemic response curves for the reference and tested food items. The repeated measures analysis of variance revealed an expected significant main effect for treatment on blood glucose values $\left(\mathrm{F}(2,28)=21.153, P<0.0001, \mathrm{\eta}_{\mathrm{p}}{ }^{2}=0.602\right)$, with significantly higher response following reference food compared with dried Tamr dates (mean difference: $0.606 \mathrm{mmol} / \mathrm{L}$; 95\% CI: 0.257, 0.956; $P=0.001$ ), and dried Bisr dates (mean difference: $0.648 \mathrm{mmol} / \mathrm{L}$; 95\% CI: 0.371, 0.926 ; $P<0.0001$ ), and no differences between dried Tamr and dried Bisr dates $(P>0.05)$. Additionally, a significant main effect due to time was observed $(\mathrm{F}(2.124,29.734)=62.488$, $\left.P<0.0001, \eta_{\mathrm{p}}^{2}=0.817\right)$. Furthermore, the analysis detected a significant interaction between treatment and time $\left(\mathrm{F}(4.824,67.535)=4.750, P<0.0001, \mathrm{\eta}_{\mathrm{p}}^{2}=0.253\right)$. Blood glucose response values were not significantly affected by trial order $(P>0.05)$.

The calculated IAUC's values for the reference food and the two test foods are shown in Figure 2. The repeated measures ANOVA demonstrated a significant main effect for treatment (type of food) on IAUC $(F(2,28)=46.375$,

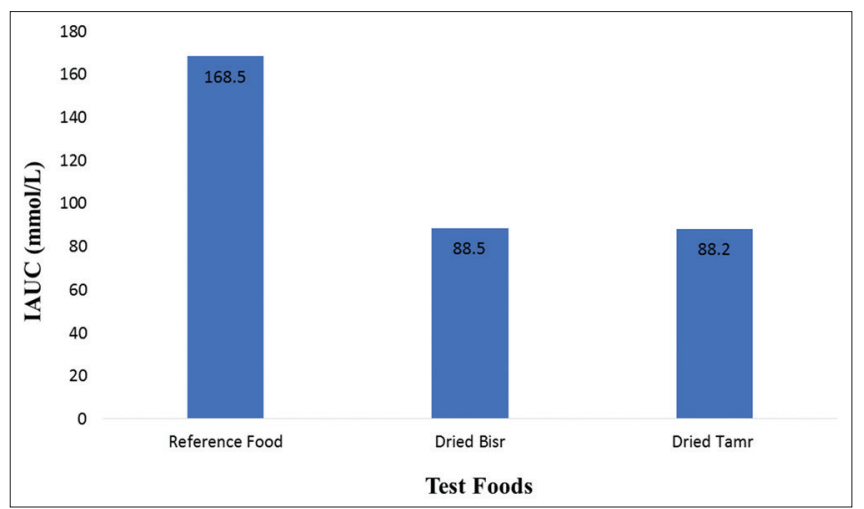

Fig 2. The IAUC values for the reference and the test foods. *Test food differed significantly from reference food $(P<0.05)$.

$\left.P<0.0001, \eta_{\mathrm{p}}^{2}=0.768\right)$, with reference food IAUC being higher $(164.5 \pm 47.8)$ in comparison with dried Bisr $(88.5$ $\pm 24.1, P<0.0001)$ or dried Tamr dates $(88.2 \pm 27.9$, $P<0.0001$ ), while no significant differences were detected between the test foods $(P>0.05)$.

\section{GI and GL classification of test foods}

The GI test is based on $25 \mathrm{~g}$ of available carbohydrate in each test food, defined as the total carbohydrate minus the dietary fiber. Table 3 shows the portion size of each test food, GI and GL values and the classification of the test foods. The GI values for test foods were 54.6 and 54.3 for dried Bisr and dried Tamr dates, respectively, classifying them as low GI foods. However, the GL values for the two tested foods were comparable and fall into the medium-GL category. (Gilbertson et al., 2001: Alkaabi et al., 2011).

\section{DISCUSSION}

Dates are the main fruit in Arabian Gulf Countries including the UAE; they are widely consumed there and in most other Middle Eastern and Islamic countries. They are one of the most significant commercial crops and have also been documented in the Holy Quran. However, there is little information available about GI and GL of different date varieties. For practical applications, GIs are often grouped into low $(<55)$, medium (56-69), or high ( $\geq 70)$ glycemic response categories (Miller et al., 2003).

A similar GL classification system is used, in which foods are categorized as having low $(\leq 10)$, medium $(10-20)$ or high GL ( $\geq 20)$ (Miller et al., 2003).

Date fruits can be consumed during three stages of maturity namely: Bisr (or Khalat), Rutab and Tamr. People in the Arabian Gulf region consume Rutab (ripe dates) in summer and Tamr (dried dates) in all seasons. Khalal (Bisr) and dried dates are considered good sources of 
Jarrar, et al.

Table 3: Glycemic index (Gl) and glycemic load (GL) values and classification of dried Bisr and dried Tamr dates

\begin{tabular}{|c|c|c|c|c|c|c|c|}
\hline \multirow[t]{2}{*}{ Test food } & \multirow[t]{2}{*}{ Available $\mathrm{CHO}(\mathrm{g})$} & \multirow[t]{2}{*}{ Experimental portion (g) } & \multicolumn{2}{|c|}{ GI } & \multirow[t]{2}{*}{ GI classification } & \multirow[t]{2}{*}{ GL } & \multirow[t]{2}{*}{ GL classification } \\
\hline & & & Mean & SD & & & \\
\hline Dried Bisr & 25 & 37.5 & 54.6 & 15.2 & Low & 13.65 & Medium \\
\hline Dried Tamr & 25 & 35.3 & 54.3 & 14.3 & Low & 13.58 & Medium \\
\hline$P$ value & & & 0.913 & & & 0.889 & \\
\hline
\end{tabular}

some nutrients, such as ascorbic acid, carotene and many phytochemicals (Sidhu, 2007).

To the best of our knowledge, the current study is the first to analyze the composition and GI of date fruits at the Bisr stage. The findings on Tamr obtained in this study are similar to those reported in other international studies (Alkaabi et al., 2011: Miller et al., 2003: Gilbertson et al., 2001). The low GI values observed for dried dates and dried Bisr were similar to those reported in Sabaka, Nabtat-seyf, Ruthana, Rashodia, Wannanah, Shishi, Sag'ai, Sukkary and Shaqra dates (AlGeffari et al., 2016). The similarity was also seen with GIs of the five types of dates popular in the UAE; Fara'd, Lulu, Bo ma'an, Dabbas and Khalas (Alkaabi et al., 2011).

The fiber content varies depending on the type and degree of ripeness (Baliga et al., 2011). The percentage of fiber decreases throughout the stages of maturation with the lowest percentage at the Tamr stage (Baliga et al., 2011: Bouaziz et al., 2013). This explains the significant differences between Bisr and dried Tamr date in fiber content $(21.3 \pm 2.0$ vs. $9.6 \pm 1.4 ; P=0.015)$ respectively. International tables suggest that the mean GI \pm SEM for dates is 42 , which is low GI.

The low GI value for dried dates (Tamr) and dried Bisr dates may be attributed to high fructose contents as reported by (Alkaabi et al., 2011) as in Fara'd, Lulu, Bo ma'an, Dabbas and Khalas dates. In 2008, Elleuch (Elleuch et al., 2008) observed that Bisr dates contain more of the health-promoting dietary fiber and less sugar than Rutab and Tamr dates. It has been suggested that dietary fiber may reduce the postprandial blood glucose responses, simply by reducing the speed of absorption of carbohydrates as a result of the formation of a viscous gel-like structure in the gastrointestinal tract (Ali et al., 2009).

GL is a useful measure of the true glycemic response because it considers portion size. Although a higher GI and GL both suggest that a food could cause a significant increase in blood glucose levels, GL considers realistic portion sizes and so could be more accurate (Griffith et al., 2008).

GL values for both test food items were intermediate, which is similar to Sabaka, Nabtat-seyf, Ruthana, Rashodia,
Wannanah, Shishi, Sag'ai, and Sukkary dates (AlGeffari et al., 2016). The GL for dried dates and dried Bisr can be reduced if the portion size of consumed dates is adjusted to $27 \mathrm{~g}$ for both types, which is equivalent to 3 to 4 dried dates. In addition, consuming dates with yogurt and cheese can further reduce GI and GL (Flint et al., 2004: Henry et al., 2006). The implication of these results is that consumption of dates in similar quantities as were used in this study will not result in rapid or large fluctuations in blood sugar even when eaten alone. Furthermore, a low GI diet demonstrably improves HbA1c levels, body weight and the lipid profile, as was seen in other studies (Ford and Liu, 2001: Buyken et al., 2001). Although dates have long been referred to as 'the candy that grows on trees', it would seem they are not like candy in terms of the glycemic response to their ingestion, which is consider as good news for diabetic individuals. Low GI has also been reported for other fruit such as berries and it was suggested that the fiber and/ or polyphenols present in lingonberries null the glycemic effect of the sugars present in the berries (Linderborg et al., 2012).

\section{CONCLUSION}

This study shows that date fruits, at the Bisr and Tamr stages, have similar effects to those of berries, although the reason for this phenomenon is not known. In addition, GI for dried Bisr and dried Tamr are low with moderate GL, which indicates similar glycemic responses regardless of their maturity stage.

\section{ACKNOWLEDGEMENTS}

The authors thank UAEU for sponsoring the project "Broadening Innovative Solution Rooms for Dates (BISR Dates)"

\section{Author Contribution}

Conceptualization: AKE, ASA; methodology: ASA, AKE, and AHJ; supervision of experiment:s: ASA, AKE, and AHJ; data analysis: ASA, AHJ, and MFB; resources: AKE; writing - original draft preparation: AHJ, ASA and MFB; writing — review and editing: ASA, AHJ, MFB, and AKE; funding acquisition: AKE. All authors read and approved the final manuscript. 


\section{Funding}

This study was funded by United Arab Emirates University through UAEU-NRF round 3 research grant competition 2012/2013 (grant number 31F022).

\section{Competing interests}

The authors declare that they have no competing interests.

\section{REFERENCES}

Al Dhaheri, A. S., A. K. Al Ma'awali, L. C. Laleye, S. A. Washi, A. H. Jarrar, F. T. Al Meqbaali, M. N. Mohamad and E. M. Masuadi. 2015. The effect of nutritional composition on the glycemic index and glycemic load values of selected Emirati foods. BMC Nutr. 1: 4.

Aldhaheri, A., G. Alhadrami, N. Aboalnaga, I. Wasfi and M. Elridi. 2004. Chemical composition of date pits and reproductive hormonal status of rats fed date pits. Food Chem. 86: 93-97.

Algeffari, M. A., E. S. Almogbel, H. T. Alhomaidan, R. El-Mergawi and I. A. Barrimah. 2016. Glycemic indices, glycemic load and glycemic response for seventeen varieties of dates grown in Saudi Arabia. Ann. Saudi Med. 36: 397-403.

Ali, A., Y. S. Al-Kindi and F. Al-Said. 2009. Chemical composition and glycemic index of three varieties of Omani dates. Int. J. Food Sci. Nutr. 60: 51-62.

Alkaabi, J. M., B. Al-Dabbagh, S. Ahmad, H. F. Saadi, S. Gariballa and M. Al Ghazali. 2011. Glycemic indices of five varieties of dates in healthy and diabetic subjects. Nutr. J. 10: 59.

Amano, Y., K. Kawakubo, J. Lee, A. Tang, M. Sugiyama and K. Mori. 2004. Correlation between dietary glycemic index and cardiovascular disease risk factors among Japanese women. Eur. J. Clin. Nutr. 58: 1472.

AOAC and W. Horwitz. 2003. Official Methods of Analysis of the AOAC International, Association of Official Analytical Chemists. AOAC, Washington, DC.

Baliga, M. S., B. R. V. Baliga, S. M. Kandathil, H. P. Bhat and P. K. Vayalil. 2011. A review of the chemistry and pharmacology of the date fruits (Phoenix dactylifera L.). Food. Res. Int. 44: $1812-1822$.

Bouaziz, M. A., S. Besbes, C. Blecker and H. Attia. 2013. Chemical composition and some functional properties of soluble fibroprotein extracts from Tunisian date palm seeds. Afr. J. Biotechnol. 12: 1121-1131.

Brouns, F., I. Bjorck, K. N. Frayn, A. L. Gibbs, V. Lang, G. Slama and T. M. S. Wolever. 2005. Glycaemic index methodology. Nutr. Rev. 18: 145-171.

Buyken, A. E., M. Toeller, G. Heitkamp, B. Karamanos, R. Rottiers, M. Muggeo. and J. H. Fuller. 2001. Glycemic index in the diet of European outpatients with Type 1 diabetes: Relations to glycated hemoglobin and serum lipids. Am. J. Clin. Nutr. 73: 574-581.

Chang, C. I., C. Y. Chen, K. C. Huang, C. H. Wu, C. A. Hsiung and C. C. Hsu. 2013. Comparison of three BIA muscle indices for sarcopenia screening in old adults. Eur. Geriatr. Med. 4: 145149.

Dashti, B. H., F. Al-Awadi, M. S. Khalafawi, S. Al-Zenki and W. Sawaya. 2001. Nutrient contents of some traditional Kuwaiti dishes: Proximate composition and phytate content. Food Chem. 74: 169-175.

Degefa, B. A., S. Muhammad and E. Fathelrahman. 2017. Market acceptability of dried dates at the unripe "Bisr" stage in United Arab Emirates. Emir. J. Food Agric. 29: 674-684.

Elleuch, M., D. Bedigian, O. Roiseux, S. Besbes, C. Blecker H. and Attia. 2011. Dietary fibre and fibre-rich by-products of food processing: Characterisation, technological functionality and commercial applications: A review. Food Chem. 124: 411-421.

Elleuch, M., S. Besbes, O. Roiseux, C. Blecker, C. Deroanne, N. E. Drira and H. Attia. 2008. Date flesh: Chemical composition and characteristics of the dietary fibre. Food Chem. 111: 676-682.

Eltayeb, E. A., A. S. Al-Hasni and S. A. Farooq. 1999. Changes in soluble sugar content during the development of fruits in some varieties of omani date palm Phoenix dactylifera. Pak. J. Biol. Sci. 2: 255-258.

FAO/WHO. 1998. Carbohydrates in Human Nutrition. Report of a Joint FAO/WHO Expert Consultation. FAO Food and Nutrition Paper No. 66. FAO, Rome.

Flint, A., B. K. Moller, A. Raben, D. Pedersen, I. Tetens, J. J. Holst and A. Astrup. 2004. The use of glycaemic index tables to predict glycaemic index of composite breakfast meals. Br. J. Nutr. 91: 979-989.

Ford, E. S. and S. Liu. 2001. Glycemic index and serum high-density lipoprotein cholesterol concentration among US adults. Arch. Intern. Med. 161: 572-576.

Gibson, R. S. 2005. Principles of Nutritional Assessment. Oxford University Press, New York.

Gilbertson, H. R., J. C. Brand-Miller, A. W. Thorburn, S. Evans, P. Chondros and G. A. Werther. 2001. The effect of flexible low glycemic index dietary advice versus measured carbohydrate exchange diets on glycemic control in children with Type 1 diabetes. Diabetes Care. 24: 1137-1143.

Griffith, J. A., Y. Ma, L. Chasan-Taber, B. C. Olendzki, D. E. Chiriboga, E. J. Stanek $3^{\text {rd }}$, P. A. Merriam and I. S. Ockene. 2008. Association between dietary glycemic index, glycemic load, and high-sensitivity C-reactive protein. J. Nutr. 24: 401-406.

Henry, C. J., H. J. Lightowler, F. L. Kendall and M. Storey. 2006. The impact of the addition of toppings/fillings on the glycaemic response to commonly consumed carbohydrate foods. Eur. J. Clin. Nutr. 60: 763-769.

IDF. 2015. IDF Diabetes Atlas. $7^{\text {th }}$ ed. International Diabetes Federation, Brussels, Belgium.

ISO 2010. Food Products-Determination of the Glycaemic Index (GI) and Recommendation for Food Classification. International Standards Organisation.

Kamal-Eldin, A., I. B. Hashim and O. I. Mohamed. 2012. Processing and utilization of palm date fruits for edible applications. Recent Pat. Food Nutr. Agric. 4: 78-86.

Kris, Y., R C. Lok, D. Chan, L. Li, G. Leung, J. Woo, H. J. Lightowler and C. J. Henry. 2010. Glycaemic index and glycaemic load values of a selection of popular foods consumed in Hong Kong. Br. J. Nutr., 103: 556-560.

Li, S. C., Y. H. Liu, J. F. Liu, W. H. Chang, C. M. Chen and C. Y. Chen. 2011. Almond consumption improved glycemic control and lipid profiles in patients with Type 2 diabetes mellitus. Metabolism. 60: 474-479.

Linderborg, K. M., R. Järvinen, H. M. Lehtonen, M. Viitanen and H. P. Kallio. 2012. The fiber and/or polyphenols present in lingonberries null the glycemic effect of the sugars present in the berries when consumed together with added glucose in healthy human volunteers. Nutr. Res. 32: 471-478.

MAF. 2000. MAF: Statistics. Ministry of Agriculture and Fisheries. Al Ain, UAE. Availabe from: http://fcsa.gov.ae/en-us/Pages/ Statistics/Statistics-by-Subject.aspx\#/\%3Fyear=2017\&folder=A griculture\%20and\%20Environment/Agriculture/Agriculture\%20 
Areas\%20and\%20Crops. [Last accessed on 2017 May 18].

Miller, C., E. Dunn and I. Hashim. 2003. The glycaemic index of dates and date/yoghurt mixed meals. Are dates 'the candy that grows on trees'? Eur. J. Clin. Nutr. 57: 427-430.

Miller, C. J., E. V. Dunn and I. B. Hashim. 2002. Glycemic index of 3 varieties of dates. Saudi Med. J. 23: 536-538.

Sidhu, J. 2007. Chemical composition of date fruits at different stages of maturity from five cultivars. FASEB J. 21: A314.
WHO. 2006. BMI Classification. World Health Organization, Geneva.

Wolever, T., H. Vorster, I. Björck, J. Brand-Miller, F. Brighenti, J. Mann, D. Ramdath, Y. Granfeldt, S. Holt and T. Perry. 2003. Determination of the glycaemic index of foods: Interlaboratory study. Eur. J. Clin. Nutr. 57: 475.

Wolever, T. M., D. J. Jenkins, A. L Jenkins and R. G. Josse. 1991. The glycemic index: Methodology and clinical implications. Am. J. Clin. Nutr. 54: 846-854. 